ISSN 1996-1944

www.mdpi.com/journal/materials

Article

\title{
Visible-Light Active and Magnetically Recyclable Nanocomposites for the Degradation of Organic Dye
}

\section{Helin Niu ${ }^{1}$ * Qinmin Wang ${ }^{1}$, Hongxia Liang ${ }^{1}$, Min Chen ${ }^{2}$, Changiie Mao ${ }^{1}$, Jiming Song ${ }^{1}$, Shengyi Zhang ${ }^{1}$, Yuanhao Gao ${ }^{3}$ and Changle Chen ${ }^{2, *}$}

1 Anhui Province Key Laboratory of Environment-friendly Polymer Materials,

School of Chemistry and Chemical Engineering, Anhui University, Hefei 230601, Anhui, China;

E-Mails: qinminwang12@gmail.com (Q.W.); hongxia828@gmail.com (H.L.); maocj2011@gmail.com (C.M.); songjm@ustc.edu.cn (J.S.); syzhangi@126.com (S.Z.)

2 CAS Key Laboratory of Soft Matter Chemistry, Department of Polymer Science and Engineering, University of Science and Technology of China, Hefei 230026, Anhui, China;

E-Mail: misschen@mail.ustc.edu.cn

3 School of Chemistry and Chemical Engineering, Xuchang University, Xuchang 461000, Henan, China; E-Mail: yuanhaogao2@gmail.com

* Authors to whom correspondence should be addressed; E-Mails: niuhelin@ahu.edu.cn (H.N.); changle@ustc.edu.cn (C.C.).

Received: 2 April 2014 / in revised form: 7 May 2014 / Accepted: 13 May 2014 /

Published: 21 May 2014

\begin{abstract}
Recyclable visible-light photocatalyst $\mathrm{Fe}_{3} \mathrm{O}_{4} @ \mathrm{TiO}_{2}$ with core-shell structure was prepared by a simple synthetic strategy using solvothermal crystallization of titanium precursor on preformed $\mathrm{Fe}_{3} \mathrm{O}_{4}$ nanopartiles. The photo-degradation reaction of neutral red aqueous solution was tested to evaluate the visible-light photocatalytic activity of the as prepared $\mathrm{Fe}_{3} \mathrm{O}_{4} @ \mathrm{TiO}_{2}$ nanoparticles, which show excellent photocatalytic activity compared with commercial P25 catalyst. Moreover, the $\mathrm{Fe}_{3} \mathrm{O}_{4} @ \mathrm{TiO}_{2}$ nanocomposites can be easily separated from the reaction mixture, and maintain favorable photocatalytic activity after five cycles. The high visible light absorption of the $\mathrm{Fe}_{3} \mathrm{O}_{4} @ \mathrm{TiO}_{2}$ nanocomposites may originate from the absence of electronic heterojunction, excellently dispersity and the high specific surface area of the as-synthesized $\mathrm{Fe}_{3} \mathrm{O}_{4} @ \mathrm{TiO}_{2}$ samples.
\end{abstract}

Keywords: magnetic photocatalysts; synthesis; $\mathrm{TiO}_{2}$; visible-light irradiation 


\section{Introduction}

Pollutions of commercial dyes have become one of the most serious environmental issues. Recently, photo-catalysis using sunlight has emerged as one of the most attractive techniques for various environmental applications such as wastewater treatment. As the most commonly used photo-catalyst, $\mathrm{TiO}_{2}$ has been extensively studied for the detoxification of wastewater [1,2]. However, its large-scale application has been limited due to the following disadvantages: (1) The large band gap $\left(E_{\mathrm{g}}=3.2 \mathrm{eV}\right)$ means it can only be excited by ultraviolet (UV) light, which is only about $4 \%$ of solar spectrum [3]; (2) The low barrier for the recombination of photogenerated electron-hole pairs reduces the quantum efficiency and the photo-catalytic activity [4]. Extensive efforts have been made to develop $\mathrm{TiO}_{2}$ photo-catalysts that can more efficiently utilize solar or indoor light. Some reports have demonstrated that the introduction of nonmetal [5-8], lanthanide ions [9,10], transitional metal ions [11-13], noble metals [14] and metallic oxides [15] into $\mathrm{TiO}_{2}$ lattice can reduce the recombination of electron-hole pairs and enhance its absorption in visible region. However, there have been very few examples about the photocatalyst possessing both visible-light activity and magnetic properties.

Core-shell structured materials combine the properties of two or several materials by synergistic effect, which may lead to unique properties. $\mathrm{Fe}_{3} \mathrm{O}_{4} @ \mathrm{TiO}_{2}$ composite system has attracted a lot of attention due to its magnetic property. However, most of the previously reported $\mathrm{Fe}_{3} \mathrm{O}_{4} @ \mathrm{TiO}_{2} \mathrm{systems}$ suffer from dramatically reduced photocatalytic activities due to the electron-hole recombination resulting from the electronic heterojunction between the core-shell $\mathrm{Fe}_{3} \mathrm{O}_{4} @ \mathrm{TiO}_{2}$ structures [16,17]. An alternative strategy was developed to solve this issue by coating the $\mathrm{Fe}_{3} \mathrm{O}_{4}$ core with $\mathrm{SiO}_{2}$ insulation layer to avoid unfavorable heterojunction and photodissolution. However, the high temperature (around $500{ }^{\circ} \mathrm{C}$ ) treatment required during the synthesis usually led to the loss of magnetism, change of iron oxide phase or the generation of mixed iron/titanium oxide [18-23]. Moreover, most of these composite systems only respond to UV light irradiation [24-26]. The development of both magnetically and photocatalytically active catalyst systems is very challenging.

Herein, we report a novel synthetic route for the preparation of recyclable Visible-light photocatalyst $\mathrm{Fe}_{3} \mathrm{O}_{4} @ \mathrm{TiO}_{2}$ under relatively low temperature (Scheme 1). The method leads to excellently dispersed and homogeneous nanoparticles by avoiding the growing and reuniting of powders. Due to the low synthetic temperature, the magnetic properties and photocatalytic activity of the composites do not deteriorate [27]. The as-prepared materials have higher visible-light absorption and much higher photo-catalytic activity in neutral red decomposition reaction comparing with commercial P25 and can be easily separated and recycled by simple utilization of a magnetic bar.

Scheme 1. Synthetic route to $\mathrm{Fe}_{3} \mathrm{O}_{4} @ \mathrm{TiO}_{2}$ core-shell nanocomposites.

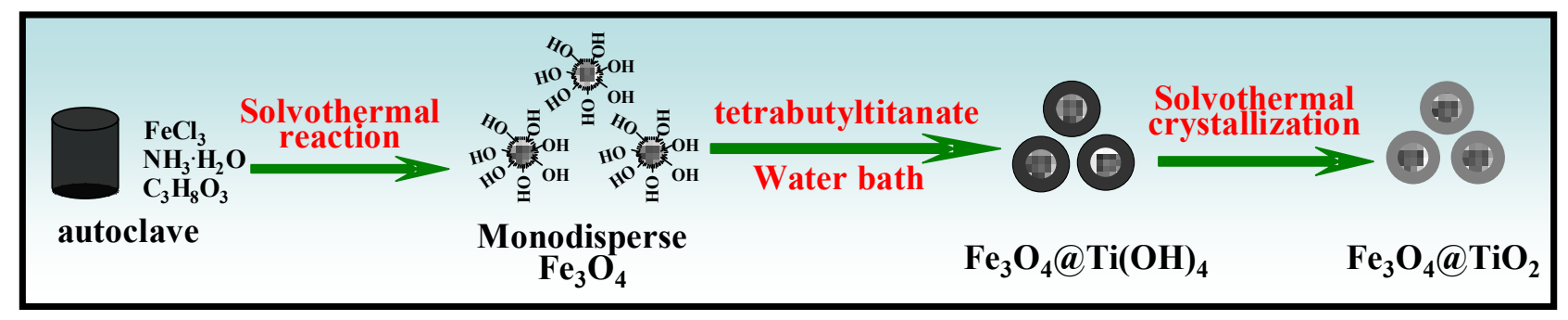




\section{Results and Discussion}

The XRD patterns of the $\mathrm{Fe}_{3} \mathrm{O}_{4}$ and $\mathrm{Fe}_{3} \mathrm{O}_{4} @ \mathrm{TiO}_{2}$ nanocomposites prepared under different temperature and different time were shown in Figures 1A,B, which showed that the as prepared samples are of high purity. The samples were scanned from $20^{\circ}$ to $80^{\circ}, 2 \theta$ degrees using a $\mathrm{Cu} \mathrm{K} \alpha$ radiation with a characteristic wavelength $(\lambda)$ of $0.15405 \mathrm{~nm}$. The $\mathrm{Fe}_{3} \mathrm{O}_{4}$ nanoparticles exhibit a broad peak at about $2 \theta=35.2^{\circ}$ (Figure 1A,B), which is the (311) reflection and has highly crystalline cublic spinel structure, agreeing well with the standard $\mathrm{Fe}_{3} \mathrm{O}_{4}$ XRD spectrum (JCPDS card No. 89-3854). Figures 1A-b and 2B-b are the XRD patterns of predecessor of $\mathrm{Fe}_{3} \mathrm{O}_{4} @ \mathrm{TiO}_{2}$. The weak diffraction peaks of $\mathrm{Fe}_{3} \mathrm{O}_{4}$ were observed. The diffraction peaks of $\mathrm{TiO}_{2}$ are stronger and broader with the increasing of the reaction temperature from Figure $1 \mathrm{~A}(\mathrm{c}-\mathrm{g})$ and the reaction time from Figure $1 \mathrm{~B}(\mathrm{c}-\mathrm{f})$. These peaks can be attributed to (101), (105) and (220) reflections of anatase $\mathrm{TiO}_{2}$, agreeing well with the standard anatase $\mathrm{TiO}_{2}$ XRD spectrum (JCPDS card No. 89-4203). The iron compound peaks in the XRD patterns became weaker and weaker, due to the formation of the $\mathrm{TiO}_{2}$ shell on the surface of iron oxide. Scherrer method was used to determine the grain size Scherrer based on the (101), (331) and (440) reflection equation as follows [28]:

$$
D=K \lambda / \beta \cos \theta
$$

where $D$ is the average diameter of the calculated particles; $K$ is the shape factor of the average grain size (the expected shape factor is 0.89 ); $\lambda$ is the wavelength characteristic in $\AA$ (in this particular case $\lambda=1.5405 \AA$ ); $\beta$ is the width of the $\mathrm{X}$-ray peak at half its high. The average crystallites size of $\mathrm{Fe}_{3} \mathrm{O}_{4} @ \mathrm{SiO}_{2}$ prepared at different temperatures of $200{ }^{\circ} \mathrm{C}, 175{ }^{\circ} \mathrm{C}, 150{ }^{\circ} \mathrm{C}$ and $135{ }^{\circ} \mathrm{C}$ are $18.6 \mathrm{~nm}$, $22.4 \mathrm{~nm}$ and $22.8 \mathrm{~nm}$ and $24.8 \mathrm{~nm}$. The average crystallites size of $\mathrm{Fe}_{3} \mathrm{O}_{4} @ \mathrm{SiO}_{2}$ prepared at different times at $10 \mathrm{~h}, 8 \mathrm{~h}, 6 \mathrm{~h}, 4 \mathrm{~h}$ are $18.6 \mathrm{~nm}, 19.1 \mathrm{~nm}, 22.1 \mathrm{~nm}$ and $22.6 \mathrm{~nm}$. High temperature and long reaction time lead to smaller crystallites. Based on the XRD spectrum analysis, the optimal solvothermal crystallization condition is $200^{\circ} \mathrm{C}$ and $8 \mathrm{~h}$.

Figure 1. (A) XRD spectra of different samples of (a) $\mathrm{Fe}_{3} \mathrm{O}_{4}$ and $\mathrm{Fe}_{3} \mathrm{O}_{4} @ \mathrm{TiO}_{2}$ of prepared at different temperatures of (b) $0{ }^{\circ} \mathrm{C}$, (c) $100{ }^{\circ} \mathrm{C}$, (d) $125^{\circ} \mathrm{C}$, (e) $150{ }^{\circ} \mathrm{C}$, (f) $175^{\circ} \mathrm{C}$, (g) $200{ }^{\circ} \mathrm{C}$; (B) XRD spectra of different samples of (a) $\mathrm{Fe}_{3} \mathrm{O}_{4}$ and $\mathrm{Fe}_{3} \mathrm{O}_{4} @ \mathrm{TiO}_{2}$ of prepared at different time under $200{ }^{\circ} \mathrm{C}$ of (b) $0 \mathrm{~h}$, (c) $4 \mathrm{~h}$, (d) $6 \mathrm{~h}$, (e) $8 \mathrm{~h}$, (f) $10 \mathrm{~h}$.
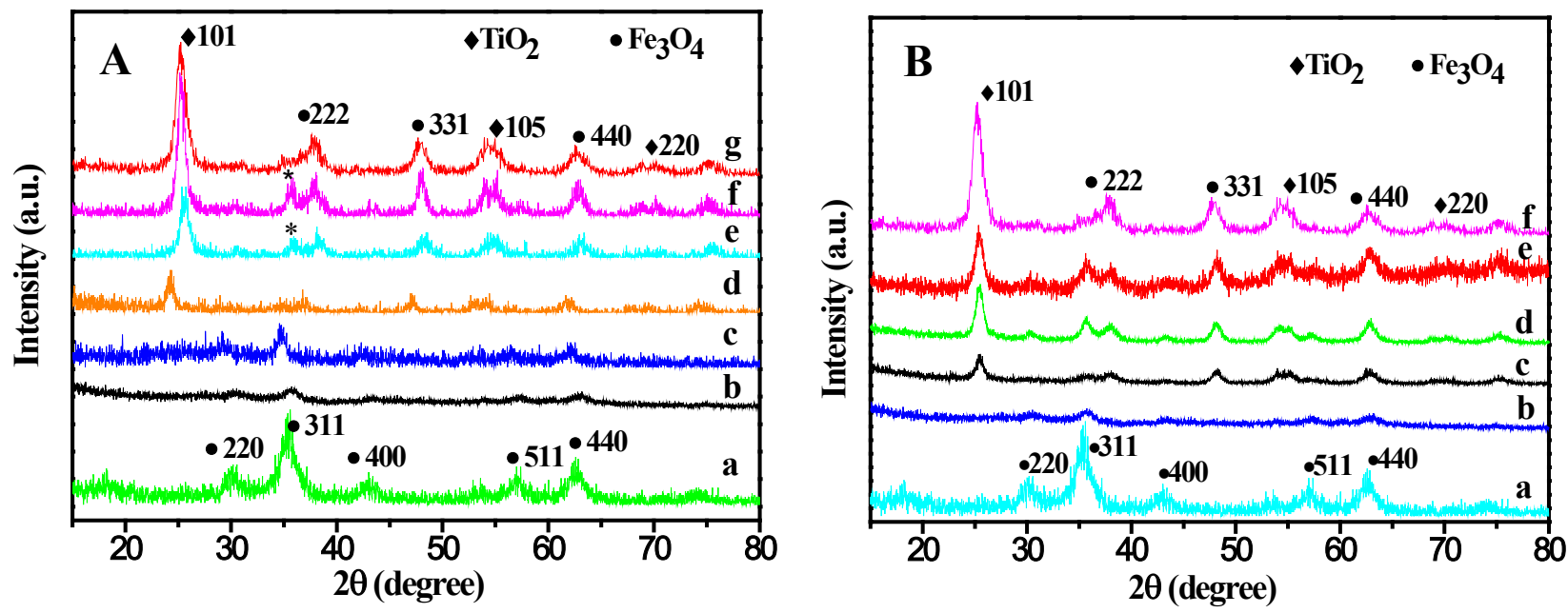
TEM image of the $\mathrm{Fe}_{3} \mathrm{O}_{4}$ nanoparticles shows excellent monodispersity with an average diameter of $10 \mathrm{~nm}$ (Figure 2A). TEM images of the $\mathrm{Fe}_{3} \mathrm{O}_{4} @ \mathrm{TiO}_{2}$ nanocomposites indicate an average diameter of $20 \mathrm{~nm}$ and a typical core-shell structure (Figure 2B,C). The thickness for the black core $\left(\mathrm{Fe}_{3} \mathrm{O}_{4}\right)$ and shell $\left(\mathrm{TiO}_{2}\right)$ is $c a .10 \mathrm{~nm}$ and $5 \mathrm{~nm}$. HRTEM analysis shows highly crystalline structure with lattice space of $0.148 \mathrm{~nm}$ and $0.17 \mathrm{~nm}$, corresponding to the (440) plane for $\mathrm{Fe}_{3} \mathrm{O}_{4}$ and (105) plane for $\mathrm{TiO}_{2}$ (Figure 2D). SAED pattern (Figure 2E) shows a twinned structure with six diffraction rings originating from the $\mathrm{TiO}_{2}$ (101), (105), (220) planes and the $\mathrm{Fe}_{3} \mathrm{O}_{4}$ (222), (331), (440) planes, which agrees very well with the XRD patterns. The EDX analysis (Figure $2 \mathrm{~F}$ ) reveals the existence of Fe, Ti, O, C and $\mathrm{Cu}$ elements with atomic percentage of 23.46, 10.25, 33.37, 26.13, 6.79, in which $\mathrm{C}$ and $\mathrm{Cu}$ were from a copper grid with carbon film. The iron peak is weak due to the shielding of the $\mathrm{TiO}_{2}$ shell.

Figure 2. TEM images of $(\mathbf{A})$ the synthesized $\mathrm{Fe}_{3} \mathrm{O}_{4}$ nanocomposites; $(\mathbf{B}, \mathbf{C}) \mathrm{Fe}_{3} \mathrm{O}_{4} @ \mathrm{TiO}_{2}$ core-shell nanocomposites synthesized by solvothermal crystallization method; (D-F) HRTEM, SAED and EDX spectrum of $\mathrm{Fe}_{3} \mathrm{O}_{4} @ \mathrm{TiO}_{2}$ core-shell nanocomposites.

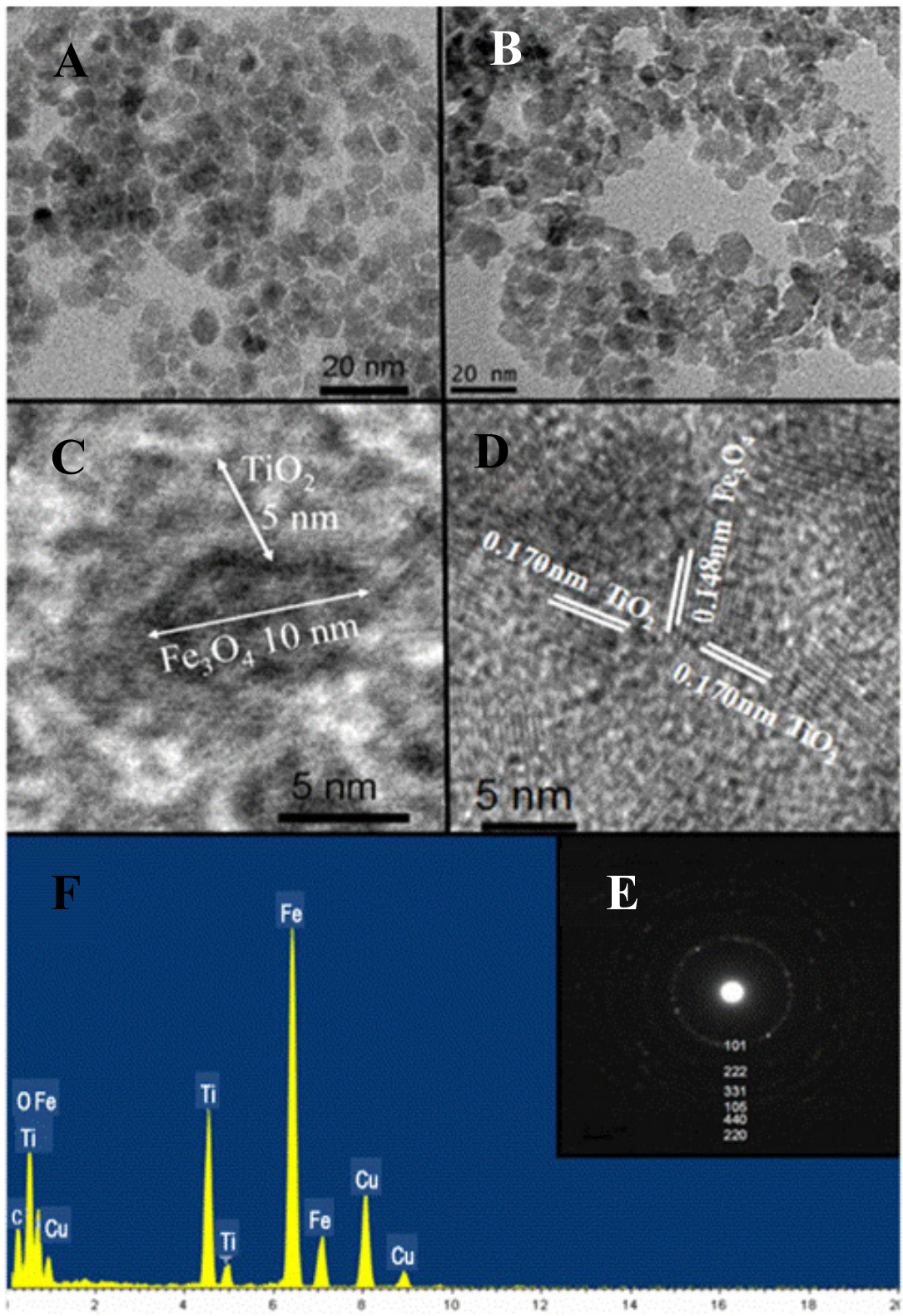


The FT-IR spectrum of the $\mathrm{Fe}_{3} \mathrm{O}_{4}$ nanoparticles (Figure 3A) shows a characteristic band for Fe-O stretching vibration at $576 \mathrm{~cm}^{-1}[29]$, the broad bands at $c a .3400 \mathrm{~cm}^{-1}$ and $1100 \mathrm{~cm}^{-1}$ are associated with the $\mathrm{O}-\mathrm{H}$ stretching and bending vibration [30,31]. These results suggested that the $\mathrm{Fe}_{3} \mathrm{O}_{4} \mathrm{surfaces}$ are linked with hydroxyl groups, which not only enables better dispersity of the $\mathrm{Fe}_{3} \mathrm{O}_{4}$ nanoparticles, but also enhances the affinity between the $\mathrm{Fe}_{3} \mathrm{O}_{4}$ nanoparticles and the predecessor $\mathrm{TiO}_{2}$. The FT-IR spectrum of the $\mathrm{Fe}_{3} \mathrm{O}_{4} @ \mathrm{SiO}_{2}$ nanoparticles (Figure 3A) shows characteristic absorption peaks at $500-750 \mathrm{~cm}^{-1}$ of titania [29], further confirming the successful preparation of the $\mathrm{Fe}_{3} \mathrm{O}_{4} @ \mathrm{TiO}_{2}$ microspheres. Nitrogen adsorption and desorption isotherms were used to investigate the specific surface area and porosity of the as-prepared $\mathrm{Fe}_{3} \mathrm{O}_{4} @ \mathrm{TiO}_{2}$ nanomaterials, and the corresponding $\mathrm{N}_{2}$ adsorption-desorption isotherms and pore size distributions are shown in Figure 3B. It can be seen that the samples have type IV isotherms (according to IUPAC classification) [27]. The Brunauer-Emmett-Teller (BET) specific surface area of the as-synthesized $\mathrm{Fe}_{3} \mathrm{O}_{4} @ \mathrm{TiO}_{2}$ samples is $160.474 \mathrm{~m}^{2} \cdot \mathrm{g}^{-1}$ by calculation from nitrogen adsorption. The single point adsorption total pore volume of pores is less than $501.4597 \mathrm{~nm}$ diameter. The high specific surface area of the sample nanostructures may provide more active sites for the catalytic reaction.

Figure 3. (A) FT-IR spectra of the as-made $\mathrm{Fe}_{3} \mathrm{O}_{4}$ nanoparticles (a) and $\mathrm{Fe}_{3} \mathrm{O}_{4} @ \mathrm{SiO}_{2}$ nanoparticles (b); (B) $\mathrm{N}_{2}$ adsorption and desorption isotherms and pore-size distribution (inset) of the $\mathrm{Fe}_{3} \mathrm{O}_{4} @ \mathrm{TiO}_{2}$; (C) M-H curves at room temperature of $\mathrm{Fe}_{3} \mathrm{O}_{4} @ \mathrm{TiO}_{2}$ and $\mathrm{Fe}_{3} \mathrm{O}_{4}$. The insert is the magnetic separation photographs of $\mathrm{Fe}_{3} \mathrm{O}_{4} @ \mathrm{TiO}_{2}$; (D) UV-Vis absorption spectrum of the $\mathrm{P} 25$ and $\mathrm{Fe}_{3} \mathrm{O}_{4} @ \mathrm{TiO}_{2}$ and the Kulbeka-Munk plot of the energy band gap.
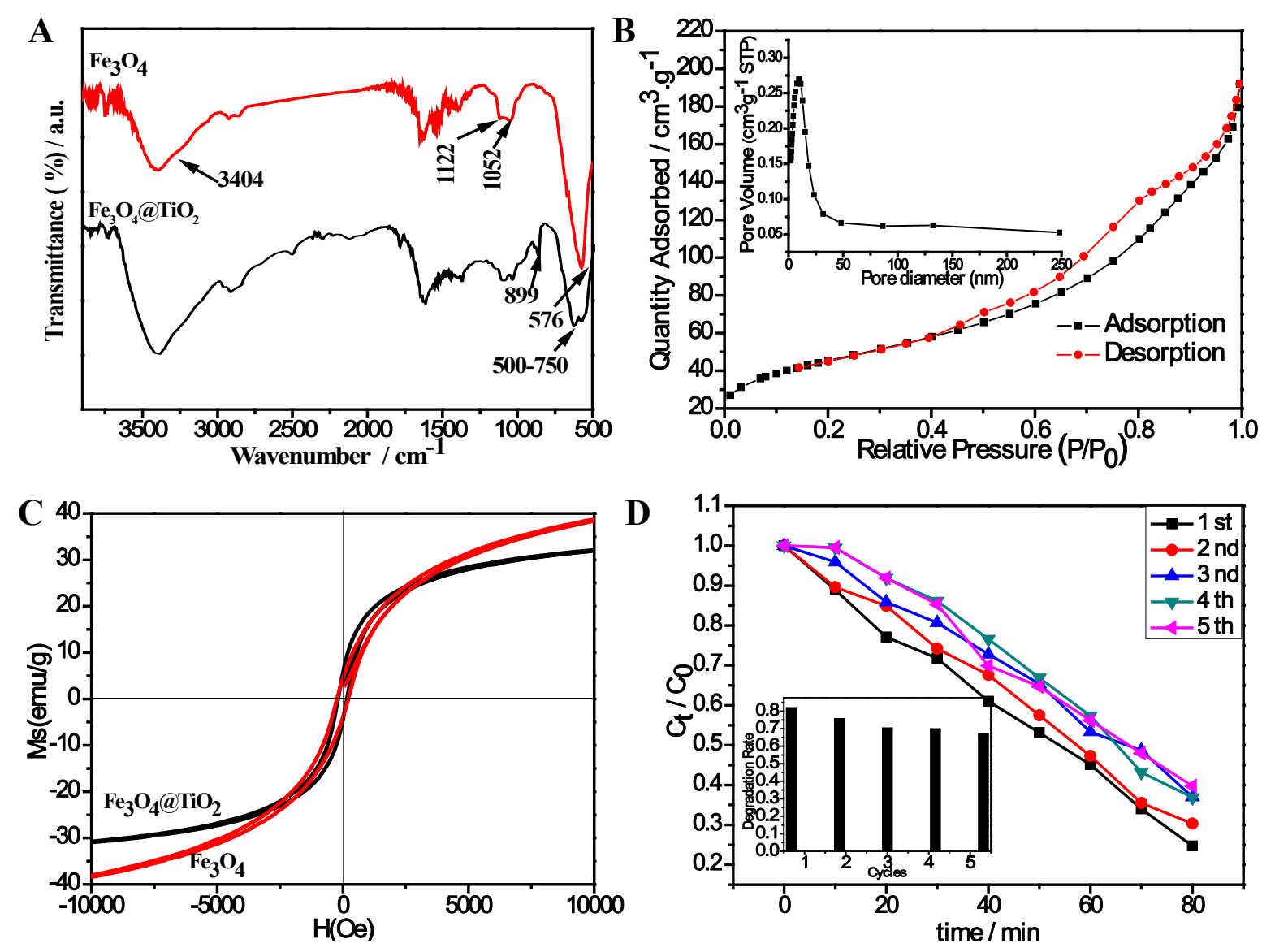
The magnetic behavior of $\mathrm{Fe}_{3} \mathrm{O}_{4} @ \mathrm{TiO}_{2}$ and $\mathrm{Fe}_{3} \mathrm{O}_{4}$ are investigated using $\mathrm{M}-\mathrm{H}$ curves from VSM analysis at room temperature (Figure 3C). The saturation magnetization value $\left(M_{\mathrm{s}}\right)$, coercivity $\left(H_{\mathrm{c}}\right)$, remanent magnetization $\left(M_{\mathrm{r}}\right)$ of $\mathrm{Fe}_{3} \mathrm{O}_{4} @ \mathrm{TiO}_{2}$ nanocomposites are $30.75 \mathrm{emu} / \mathrm{g}, 167.89 \mathrm{Oe}$ and $6.14 \mathrm{emu} / \mathrm{g}$, respectively. In contrast, the $M_{\mathrm{s}}, H_{\mathrm{c}}$ and $M_{\mathrm{r}}$ values of the $\mathrm{Fe}_{3} \mathrm{O}_{4}$ are $38.55 \mathrm{emu} / \mathrm{g}$, $229.34 \mathrm{Oe}$ and $4.6 \mathrm{emu} / \mathrm{g}$, respectively. This may due to the lower content of $\mathrm{Fe}_{3} \mathrm{O}_{4}$ in $\mathrm{Fe}_{3} \mathrm{O}_{4} @ \mathrm{TiO}_{2}$. The $\mathrm{Fe}_{3} \mathrm{O}_{4} @ \mathrm{TiO}_{2}$ sample is still considered to be superparamagnetic due to its small $H_{\mathrm{c}}$ and $M_{\mathrm{r}}$ value though individual particles may be larger than the superparamagnetic critical size $(20 \mathrm{~nm})$ [32]. From the insert in Figure 3C, it can be see that as prepared $\mathrm{Fe}_{3} \mathrm{O}_{4} @ \mathrm{TiO}_{2}$ nanocomposites can be evenly dispersed in water, and easily separated from water upon placing a small magnetic bar at one side of the bottle.

$\mathrm{Fe}_{3} \mathrm{O}_{4} @ \mathrm{TiO}_{2}$ has a broad absorption (200 800 nm) in UV-Vis analysis (Figure 3D). In contrast, commercial P25 shows minimum absorption in the $>400 \mathrm{~nm}$ range. The energy band gap of the samples as a semiconductor was calculated by the Kulbeka-Munk theory [33]. The relationship between absorption coefficient $(\alpha)$ and the incident photon energy $(h v)$ can be written as $\alpha=\mathrm{B}_{\mathrm{d}}\left(h v-E_{\mathrm{g}}\right)^{1 / 2} /(h v)$, where $B_{d}$ is the absorption constant. The Kulbeka-Munk plot of $(\alpha h v)^{1 / 2}$ versus $(h v)$ was presented in the insert. The extrapolated value of the absorption edge was about $2.10 \mathrm{eV}$. This value is much narrower than pure $\mathrm{TiO}_{2}(3.2 \mathrm{eV})$. The significant absorption in the $>400 \mathrm{~nm}$ range and the small band gap suggested its possible photocatalytic properties under visible light.

The photocatalytic properties of $\mathrm{Fe}_{3} \mathrm{O}_{4} @ \mathrm{TiO}_{2}$ composite were investigated with the degradation reaction of neutral red in aqueous solution under 400-700 nm wavelength to mimic sunlight. Figure 4B shows the UV-Vis absorbance peak of neutral red (at $530 \mathrm{~nm}$ ) [34] gradually decreased with irradiation time and completely disappeared after the reaction. Figure 4A shows that the absorbance of the neutral red solution decreases with the time in the dark. After $30 \mathrm{~min}$, there is no obvious change in absorbance, indicating that equilibrium is reached. Figure $4 \mathrm{C}$ shows the concentration profiles of neutral red during the experiment. The degradation is very slow in the presence of only dye and light (without catalyst, Figure $4 \mathrm{C}(\mathrm{a})$ ). The activity of $\mathrm{Fe}_{3} \mathrm{O}_{4} @ \mathrm{TiO}_{2}$ (Figure $4 \mathrm{C}(\mathrm{d})$ ) is much higher than that of the commercial catalyst P25 (Figure 4C-d). This is not surprising since $\mathrm{Fe}_{3} \mathrm{O}_{4} @ \mathrm{TiO}_{2}$ demonstrates significant absorption in the visible light region while P25 does not (Figure 3D).

The surprising visible light absorption and the excellent visible light photocatalytic activity might originate from the absence of electronic heterojunction, excellently dispersity and the high specific surface area of the $\mathrm{Fe}_{3} \mathrm{O}_{4} @ \mathrm{TiO}_{2}$ structures. In contrast, Sample-2 was prepared under the same conditions except $10 \mathrm{~mL}$ distilled water was used instead of $10 \mathrm{~mL}$ urea solution. Sample-2 has much lower activity than $\mathrm{P} 25$ or $\mathrm{Fe}_{3} \mathrm{O}_{4} @ \mathrm{TiO}_{2}$ composites, suggesting the crucial role of the urea. The presence of urea during the synthesis may which may introduce $\mathrm{N}$-doping in the $\mathrm{Fe}_{3} \mathrm{O}_{4} @ \mathrm{TiO}_{2}$ composites. It has been shown before that $\mathrm{N}$-doping in $\mathrm{TiO}_{2}$ can induce visible light adsorption [35-37].

Recyclability experiment was also studied (Figure 4D). After each experiment, the photocatalysts were separated by applying an external magnetic field, washed three times with ethanol, dried at $60{ }^{\circ} \mathrm{C}$ and redistributed in fresh neutral red solution. The catalyst showed favorable reusability after five times of recycling. We did observe some extent of the loss in the catalytic activity after each cycle. The decrease in the degradation rate may be due to the weakening of the absorbance ability of the catalysts or the loss of some catalysts during the collection. 
Figure 4. (A) The adsorption rate curves of neutral red test in the dark with the presence of $\mathrm{Fe}_{3} \mathrm{O}_{4} @ \mathrm{TiO}_{2}$. The insert is the adsorption curves of neutral red in the dark with the presence of $\mathrm{Fe}_{3} \mathrm{O}_{4} @ \mathrm{TiO}_{2}$ nanocomposites; (B) the photodegradation curves of neutral red under visible light in the presence of $\mathrm{Fe}_{3} \mathrm{O}_{4} @ \mathrm{TiO}_{2}$ nanocomposites; (C) the photodegradation rate curves of neutral red test in presence of only visible light without catalyst (a) and under the visible light irradiation with Sample-2 (b), P25 (c) and $\mathrm{Fe}_{3} \mathrm{O}_{4} @ \mathrm{TiO}_{2}$ nanocomposites (d); (D) the degradation rate of the neutral red by $\mathrm{Fe}_{3} \mathrm{O}_{4} @ \mathrm{TiO}_{2}$ nanocomposites. The insert is the normalized rate constant in different cycles
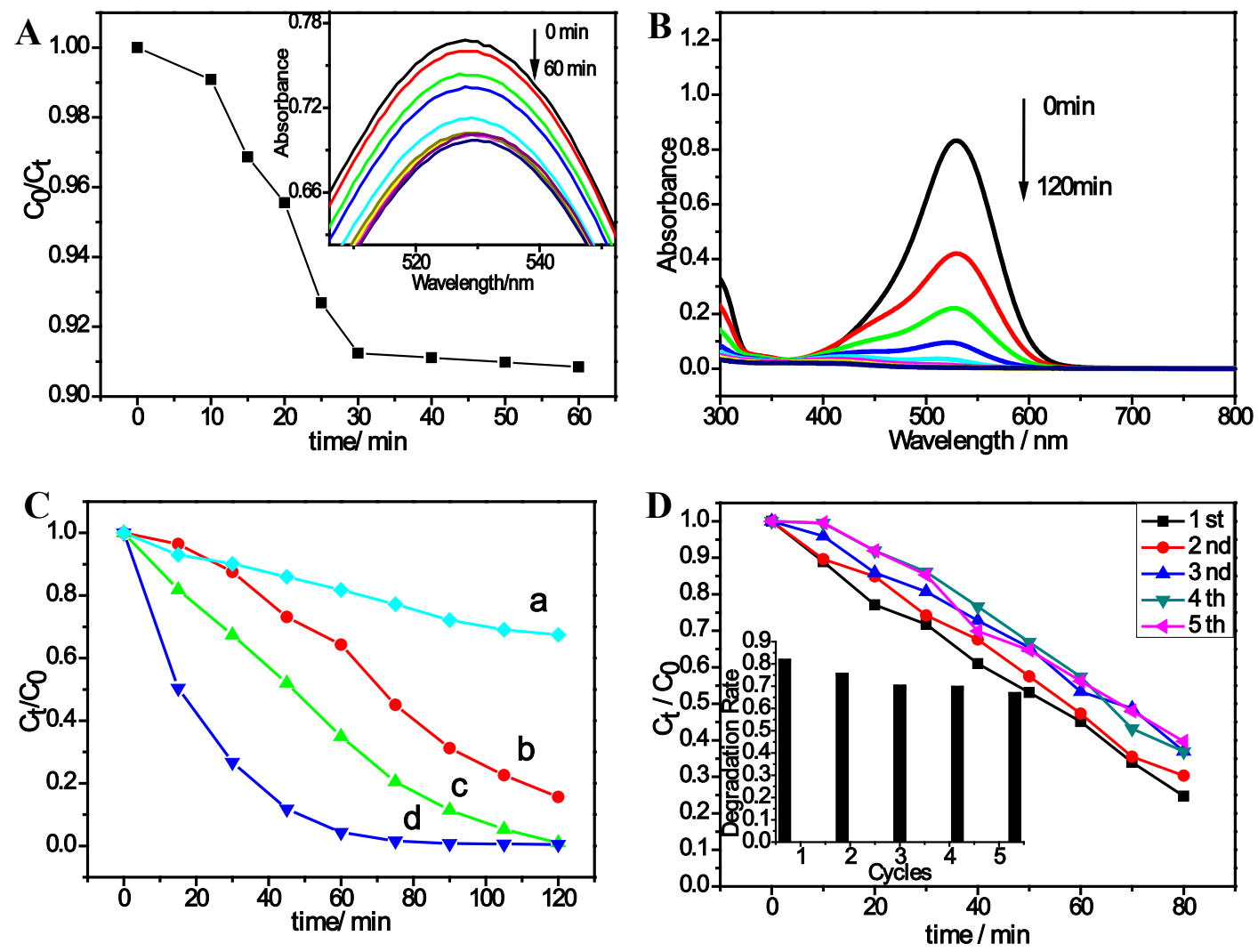

\section{Experimental Section}

\subsection{Materials}

Anhydrous $\mathrm{FeCl}_{3}$, ammonia, glycerol, tetrabutyl titanate (TBOT), polyvinylpyrrolidone (PVP), urea, absolute ethanol $\left(\mathrm{C}_{2} \mathrm{H}_{5} \mathrm{OH}\right)$. All chemicals are of analytical grade and used without any purification; Deionized water was used throughout the experiments.

\subsection{Synthesis}

Scheme 1 shows the synthetic route to $\mathrm{Fe}_{3} \mathrm{O}_{4} @ \mathrm{TiO}_{2}$ core-shell nanocomposites. $0.16 \mathrm{~g}$ anhydrous $\mathrm{FeCl}_{3}$ was fully dispersed in $5 \mathrm{~mL}$ ammonia. Fifteen $\mathrm{mL}$ glycerol was added to the above mixture, which was transferred into a Teflon-sealed autoclave. The autoclave was heated at $180{ }^{\circ} \mathrm{C}$ for $10 \mathrm{~h}$ before being cooled in air naturally. The magnetic $\mathrm{Fe}_{3} \mathrm{O}_{4}$ nanoparticles were separated by a magnet and washed three times by distilled water and redispersed in $10 \mathrm{~mL}$ absolute ethanol for subsequent 
processing. Under mechanical stirring, tetrabutyl titanate (TBOT) was diluted in absolute ethanol containing $0.08 \mathrm{~g}$ PVP and added to the $\mathrm{Fe}_{3} \mathrm{O}_{4}$ suspension. The mixture was sufficiently mixed and heated in water bath at $80^{\circ} \mathrm{C}$ for $15 \mathrm{~h}$. During this process, a mixture of $20 \mathrm{~mL}$ ethanol and $10 \mathrm{~mL}$ urea were added dropwise. Then, the suspension was aged for $12 \mathrm{~h}$ so that $\mathrm{Ti}(\mathrm{OH})_{4}$ can adsorb on the surface of the $\mathrm{Fe}_{3} \mathrm{O}_{4}$ nanoparticles. The composite particles were aggregated by an external magnetic field, and washed three times with distilled water and absolute ethanol. The magnetic particles were resuspended in a proper amount of absolute ethanol and the solution was transferred into a Teflon-sealed autoclave. The autoclave was heated to $200{ }^{\circ} \mathrm{C}$ for $8 \mathrm{~h}$, and dark brown magnetic nanocomposites were obtained. The final $\mathrm{Fe}_{3} \mathrm{O}_{4} @ \mathrm{TiO}_{2}$ core-shell nanocomposites were separated by magnet, washed three times by ethanol and oven-dried at $60{ }^{\circ} \mathrm{C}$ for 4 h. Another $\mathrm{Fe}_{3} \mathrm{O}_{4} @ \mathrm{TiO}_{2}$ core-shell nanocomposites were synthesized by the same method except $10 \mathrm{~mL}$ distilled water was used instead of $10 \mathrm{~mL}$ urea solution and designated as Sample-2.

\subsection{Evaluation Photocatalytic Activity}

The photocatalytic activity was evaluated by the degradation of neutral red aqueous solution at room temperature. Twenty $\mathrm{mg}$ catalysts were suspended in $70 \mathrm{~mL}$ dye solution $\left(10 \mathrm{mg} \cdot \mathrm{L}^{-1}\right)$. The solution was continuously stirred in the dark for $30 \mathrm{~min}$. Then, the solution was exposed to visible light from a $30 \mathrm{~W}$ xenon lamp (PLS-SXE 300, Beijing, China, and the UV light was filtered by the filter). The water samples were collected by magnetic field every $15 \mathrm{~min}$ to measure the concentration of dye solution with UV-Vis spectra. After the reaction, the magnetic catalysts were collected using a permanent magnetic field, washed with ethanol for 3 times, dried in oven at $60{ }^{\circ} \mathrm{C}$ for $4 \mathrm{~h}$, and rested for the recyclability experiment. The concentration change $\left(C / C_{0}\right)$ and the percent conversion $\left(\left(C-C_{0}\right) / C_{0}\right)$ of the dye were calculated and plotted $v s$. irradiation time.

\subsection{Characterization}

X-ray powder diffraction (XRD) of $\mathrm{Fe}_{3} \mathrm{O}_{4}$ and $\mathrm{Fe}_{3} \mathrm{O}_{4} @ \mathrm{TiO}_{2}$ core-shell nanocomposites were obtained using X-ray diffractometry (XRD, Rigaku D/max-RA, graphite monochromatized $\mathrm{CuK} \alpha$ radiation, $\lambda=1.5406 \AA$, at $36 \mathrm{kV}$ and $25 \mathrm{~mA}$ ). Transmission electron microscopy (TEM), High resolution transmission electron microscopy (HRTEM) and energy-dispersive X-ray (EDX) analysis were obtained by a JEM-2100 transmission electron microscope (accelerating voltage $=200 \mathrm{kV}$ ). IR spectra were measured by using $\mathrm{KBr}$ pellets on a NECUS-870. The ultraviolet-visible (UV-Vis) diffuse reflectance spectroscopy and the UV-Vis absorption of the products were recorded on a UV spectrometer (UV-1750). Magnetic properties of samples were evaluated on a BHV-55 vibrating sample magnetometer (VSM).

\section{Conclusions}

In summary, Recyclable visible-light active photocatalyst $\mathrm{Fe}_{3} \mathrm{O}_{4} @ \mathrm{TiO}_{2}$ with core-shell structure was prepared by a simple synthetic method under mild conditions. The as-prepared nanocomposites were characterized by XRD, TEM, UV-Vis and magnetic analysis, which showed great dispersity, high crystallinity and good magnetic property. Very surprisingly, the nanocomposites demonstrate 
significant absorption in the Visible light region and is much more active than commercial P25 in the neutral red decomposition reaction. More importantly, the photocatalyst can be easily separated by an external magnetic field and reused. After five cycles, the catalyst still maintained great catalytic activities. This method provides a simple while general strategy to improve the photocatalytic properties of $\mathrm{TiO}_{2}$ under Visible light, and introduces magnetic properties at the same time.

\section{Acknowledgments}

This work was supported by the National Natural Science Foundation of China (Grant Nos. 21071002, 21275006, 21271152 and 21374108), Anhui Provincial Natural Science Foundation (1408085QB28), Key Project of Anhui Provincial Education Department (KJ2013A029), 211 project of Anhui University and Recruitment Program of Global Experts.

\section{Author Contributions}

Qinmin Wang, Hongxia Liang, Min Chen, Changjie Mao, Jiming Song, Shengyi Zhang and Yuanhao Gao performed the preparation of the samples, the characterizations and the catalytic studies. Helin Niu and Changle Chen conceived and supervised the project. Helin Niu and Changle Chen wrote the manuscript with contributions from all authors.

\section{Conflicts of Interest}

The authors declare no conflict of interest.

\section{References}

1. Kleiman, A.; Marquez, A.; Lamas, D.G. Anatase $\mathrm{TiO}_{2}$ films obtained by cathodic arc deposition. Surf. Coat. Technol. 2007, 201, 6358-6362.

2. Behnajady, M.A.; Modirshahla, N.; Daneshvar, N.; Rabbani, M. Photocatalytic degradation of an azo dye in a tubular continuous-flow photoreactor with immobilized $\mathrm{TiO}_{2}$ on glass plates. Chem. Eng. J. 2007, 127, 167-176.

3. Nguyen, V.N.H.; Amal, R.; Beydoun, D. Photodeposition of CdSe using Se-TiO 2 suspensions as photocatalysts. J. Photoch. Photobio. A 2006, 179, 57-65.

4. Chen, J.Y.; Qian, Y.; Wei, X.Z. Comparison of magnetic-nanometer titanium dioxide/ferriferous oxide $\left(\mathrm{TiO}_{2} / \mathrm{Fe}_{3} \mathrm{O}_{4}\right)$ composite photocatalyst prepared by acid-sol and homogeneous precipitation methods. J. Mater. Sci. 2010, 45, 6018-6024.

5. Xu, Y.J.; Zhuang, Y.; Fu, X. New insight for enhanced photocatalytic activity of $\mathrm{TiO}_{2}$ by doping carbon nanotubes: A case study on degradation of benzene and methyl orange. J. Phys. Chem. C 2010, 114, 2669-2676.

6. Choi, Y.; Mebayashi, T.; Yoshikawa, U.M. Fabrication and characterization of C-doped anatase $\mathrm{TiO}_{2}$ photocatalysts. J. Mater. Sci. 2004, 39, 1834-1839.

7. Wang, D.H.; Jia, L.; Wu, X.L.; Lu, L.Q. One-step hydrothermal synthesis of N-doped $\mathrm{TiO}_{2} / \mathrm{C}$ nanocomposites with high visible light photocatalytic activity. Nanoscale 2012, 4, 576-584. 
8. Dunnill, C.W.; Parkin, I.D. Silver enhanced $\mathrm{TiO}_{2}$ thin films: Photocatalytic characterization using aqueous solutions of tris (hydroxymethyl) aminomethane. Dalton Trans. 2011, 40, 1635-1640.

9. Luo, W.Q.; Li, R.F.; Liu, Y.S.; Zhu, H.M.; Chen, X.Y. Er ${ }^{3+}$-doped anatase $\mathrm{TiO}_{2}$ nanocrystals: Crystal-field levels, excited-state dynamics, up conversion, and defect luminescence. Small 2011, 7, 3046-3056.

10. Hafez, H.; Saif, M.; Abdel-Mottaleb, M.S.A. Down-converting lanthanide doped $\mathrm{TiO}_{2}$ photoelectrodes for efficiency enhancement of dye-sensitized solar cells. J. Power. Sources. 2011, 196, 5792-5796.

11. Zhu, J.F.; Deng, Z.G.; Chen, F.; Zhang, J.L.; Chen, H.J.; Anpo, M.; Huang, J.Z.; Zhang, L.Z. Hydrothermal doping method for preparation of $\mathrm{Cr}^{3+}-\mathrm{TiO}_{2}$ photocatalysts with concentration gradient distribution of $\mathrm{Cr}^{3+}$. Appl. Catal. B 2006, 62, 329-335.

12. Cha, W.; Le, H.A.; Chin, S.; Kim, M.; Jung, H.; Yun, S.T.; Jurng, J. Enhanced low-temperature $\mathrm{NH}_{3}$-SCR activity of a $\mathrm{V}_{2} \mathrm{O}_{5} / \mathrm{TiO}_{2}$ composite prepared via chemical vapor condensation and impregnation method. Mater. Res. Bull. 2013, 48, 4415-4418.

13. Janisch, R.; Gopal, P.; Spaldin, N.A. Transition metal-doped $\mathrm{TiO}_{2}$ and $\mathrm{ZnO}$-present status of the f field. J. Phys. Condens. Matter. 2005, 17, R657-R689.

14. Li, Y.Z.; Jin, S.F.; Xie, H.; Chen, X.; Tian, T.T.; Zhao, X.J. Highly selective photocatalytic and sensing properties of $2 \mathrm{D}$ - Ordered dome of nano-titania and nano- $\mathrm{Ag}^{2+}$ doped titania. J. Mater. Chem. 2012, 22, 1469-1476.

15. Liu, L.C.; Gu, X.R.; Sun, C.Z.; Li, H.; Deng, Y.; Gao, F.; Dong, L. In situ loading of ultra-small $\mathrm{Cu}_{2} \mathrm{O}$ particles on $\mathrm{TiO}_{2}$ nanosheets to enhance the visible-light photoactivity. Nanoscale 2012, 4, 6351-6359.

16. Navio, J.; Colon, G.; Trillas, M.; Peral, J.; Domenech, X.; Testa, J.J.; Padron, J.; Rodriguez, D.; Litter, M.I. Heterogeneous photocatalytic reactions of nitrite oxidation and $\mathrm{Cr}(\mathrm{VI})$ reduction on iron-doped titania prepared by the wet impregnation method. Appl. Catal. B 1998, 16, 187-195.

17. Ranjit, K.T.; Viswanthan, B.; Photochem, J. Synthesis, characterization and photocatalytic properties of iron-doped $\mathrm{TiO}_{2}$. Catalysts. Photobiol. B 1997, 108, 79-84.

18. Yoshica, M.; Prasad, P.N. Sol-gel-processed $\mathrm{SiO}_{2} / \mathrm{TiO}_{2} /$ poly(vinylpyrrolidone) composite materials for optical waveguides. Chem. Mater. 1996, 8, 235-241.

19. Tatsuma, T.; Saitoh, S.; Ohko, Y.; Fujishima, A. $\mathrm{TiO}_{2}-\mathrm{WO}_{3}$ photoelectro chemical anticorrosion system with an energy storage ability. Chem. Mater. 2001, 13, 2838-2842.

20. Huang, J.; Shinohara, T.; Tsujikawa, S. Effects of interfacial iron oxides on corrosion protection of carbon steel by $\mathrm{TiO}_{2}$ illumination. Zairyo-to-Kankyo 1997, 469, 651-661.

21. Chen, F.; Xie, Y.D.; Zhao, J.C.; Lu, G.X. Photocatalytic degradation of dyes on a magnetically separated photocatalyst under visible and UV irradiation. Chemosphere 2001, 44, 1159-1168.

22. Xu, S.H.; Shangguan, W.F.; Yuan, J.; Chen, M.X.; Shi, J.W. Synthesis and performance of novel magnetically separable nanospheres of titanium dioxide photocatalyst with egg-like structure. Appl. Catal. B 2007, 71, 177-184.

23. Aziz, A.A.; Cheng, C.K.; Ibrahim, S.; Matheswaran, M.; Saravanan, P. Visible light improved, photocatalytic activity of magnetically separable titania nanocomposite. Chem. Eng. J. 2012, 183, 349-356. 
24. Yang, Y.; Guo, Y.H.; Hu, C.W.; Wang, Y.H.; Wang, E.B. Preparation of surface modifications of mesoporous titania with monosubstituted Keggin units and their catalytic performance for organochlorine pesticide and dyes under UV irradiation. Appl. Catal. A 2004, 273, 201-210.

25. Li, Y.X.; Zhang, M.; Guo, M.; Wang, X.D. Preparation and properties of a nano $\mathrm{TiO}_{2} / \mathrm{Fe}_{3} \mathrm{O}_{4}$ composite superparamagnetic photocatalyst. Rare Metals 2009, 28, 423-427.

26. Das, S.K.; Bhunia, M.K.; Haumik, A.B. Self-assembled $\mathrm{TiO}_{2}$ nanoparticles: Mesoporosity, optical and catalytic properties. Dalton Trans. 2010, 39, 4382-4390.

27. Zhang, Y.; Yu, X.; Jia, Y.; Jin, Z.; Liu, J.H.; Huang, X.J. A facile approach for the synthesis of Ag-coated $\mathrm{Fe}_{3} \mathrm{O}_{4} @ \mathrm{TiO}_{2}$ core/shell microspheres as highly efficient and recyclable photocatalysts. Eur. J. Inorg. Chem. 2011, 2011, 5096-5104.

28. Cullity, B.D.; Stock, S.R. Elements of X-ray Diffraction; Prentice Hall: Upper Saddle River, NJ, USA, 2001; pp. 385-433.

29. Chen, C.T.; Chen, Y.C. $\mathrm{Fe}_{3} \mathrm{O}_{4} / \mathrm{TiO}_{2}$ core/shell nanoparticles as affinity probes for the analysis of phosphopeptides using $\mathrm{TiO}_{2}$ surface-assisted laser desorption/ionization mass spectrometry. Anal. Chem. 2005, 77, 5912-5919.

30. Yeh, C.S.; Wu, M.T.; Shieh, D.B.; Cheng, F.Y.; Su, C.H.; Yang, Y.S.; Tsai, C.Y. Characterization of aqueous dispersions of $\mathrm{Fe}_{3} \mathrm{O}_{4}$ nanoparticles and their biomedical applications. Biomaterials 2005, 26, 729-738.

31. Li, Y.; Wu, J.S.; Qi, D.W.; Xu, X.Q.; Deng, C.H.; Yang, P.Y.; Zhang, X.M. Novel approach for the synthesis of $\mathrm{Fe}_{3} \mathrm{O}_{4} @ \mathrm{TiO}_{2}$ core-shell microspheres and their application to the highly specific capture of phosphopeptides for MALDI-TOF MS analysis. Chem. Commun. 2008, 5, 564-566.

32. Hao, R.; Xing, R.J.; Xu, Z.C.; Hou, Y.L.; Sun, S.H.; Gao, S. Synthesis, functionalization, and biomedical applications of multifunctional magnetic. Adv. Mater. 2010, 22, 2729-2742.

33. Zanjianchi, M.A.; Noei, H.; Moghimia, M. Rapid determination of aluminum by UV-vis diffuse reflectance spectroscopy with application of suitable adsorbents. Talanta 2006, 70, 933-939.

34. Yang, Y.; Hu, C.W.; Wu, Q.Y.; Guo, Y.H.; Wang, E. Efficient degradation of dye pollutants on nanoporous polyoxotungstate-anatase composite under visible-light irradiation. J. Mol. Catal. A Chem. 2005, 225, 203-212.

35. Asahi, R.; Morikawa, T.; Ohwaki, T.; Aoki, K.; Taga, Y. Visible-light photocatalysis in nitrogen-doped titanium oxides. Science 2001, 293, 269-271.

36. Kumar, N.; Maitra, U.; Hegde, V.I.; Waghmare, U.V.; Sundaresan, A.; Rao, C.N.R. Synthesis, characterization, photocatalysis, and varied properties of $\mathrm{TiO}_{2}$ cosubstituted with nitrogen and fluorine. Inorg. Chem. 2013, 52, 10512-10519.

37. Khataee, A.R.; Zarei, M.; Moradkhannejhad, L.; Nourie, S.; Vahid, B. Nitrogen doping of commercial $\mathrm{TiO}_{2}$ nanoparticles for enhanced photocatalytic degradation of dye under visible light: Central composite design approach. Adv. Chem. Lett. 2013, 1, 24-31.

(C) 2014 by the authors; licensee MDPI, Basel, Switzerland. This article is an open access article distributed under the terms and conditions of the Creative Commons Attribution license (http://creativecommons.org/licenses/by/3.0/). 